\title{
O ART. 28 DA DECLARAÇÃO UNIVERSAL DOS DIREITOS DO HOMEM OU A GARANTIA DA APROPRIAÇÃO EFETIVA DOS DIREITOS HUMANOS $^{1}$
}

\author{
Cláudia Perrone-Moisés \\ Professora Doutora do Departamento de Direito Internacional da \\ Faculdade de Direito da Universidade de São Paulo
}

\begin{abstract}
Resumo:
O art. 28 da Declaração Universal dos Direitos do Homem dispõe que "todo homem tem direito a uma ordem social e internacional em que os direitos e liberdades estabelecidos na presente Declaração possam ser plenamente realizados'. Entendendo a expressão "ordem internacional" como ordem econômica internacional, o presente texto propõe uma visão crítica da ordem jurídica em vigor. As normas e instituições que regulam as relações econômicas internacionais não vêm garantindo a ordem de que trata o art. 28 . Sendo assim, propõe-se que sejam aplicadas as normas que compõem o ordenamento jurídico dos Direitos Humanos, em especial o direito ao desenvolvimento, no que se refere às relações econômicas internacionais, a fim de garantir uma ordem econômica mais justa e em que se realizem plenamente os direitos e liberdades previstos na Declaração.
\end{abstract}

\begin{abstract}
:
The article 28 of the Universal Declaration on Human Rights establishes that "every man has the right to have a social and international order in which every right and freedom of the Declaration could be totally assured". Considering the expression "international order" as international economic order, this text proposes a critical view of the law that regulates international economic relations since the rules and institutions which regulate this relations are not assuring the order referred in article 28. Under these conditions we propose that the principles of human rights, specially the right to development, should be applied to regulate these relations, in order to warrant an economic order where justice prevails and the rights and freedoms established in the Declaration could be realized.
\end{abstract}

1. Esse texto foi apresentado no XXII Encontro Anual da Associação Nacional de Pós-Graduação e Pesquisa em Ciências Sociais, na Mesa-Redonda $O$ desenvolvimento como apropriação dos direitos humanos, coordenada pelos profs. Paulo Sérgio Pinheiro e Nancy Cardia, realizada em 28 de outubro de 1998. 
Unitermos: Direitos Humanos; ordem econômica internacional; direito ao desenvolvimento.

A Declaração Universal dos Direitos do Homem, que completou em dezembro cinqüenta anos, constitui, como lembra Norberto Bobbio, ${ }^{2}$ a única manifestação de consenso quanto a valores fundados no ser humano e destinados a alcançarem universal aplicação. Entre os trinta artigos da Declaração, além daqueles mais conhecidos, como o Direito à vida, à liberdade, a uma nacionalidade, à educação, e outros Direitos Fundamentais, há regras que se poderiam chamar de regras de viabilização das demais.

Proponho aqui refletir acerca de um desses artigos, que podemos também denominar regras de integração do sistema: o art. 28 da Declaração Universal. Segundo ele, "todo homem tem direito a uma ordem social $e$ internacional em que os direitos e liberdades estabelecidos na presente Declaração possam ser plenamente realizados" Em outras palavras, toda pessoa tem Direito a uma ordem que garanta a efetivação de todos os Direitos e liberdades fundamentais ou, para utilizar a expressão de Ignacy Sachs, ${ }^{3}$ todos têm direito a uma ordem onde se veja garantida a "apropriação efetiva dos Direitos Humanos".

Mas o que é essa ordem? A ordem pode ser entendida como ordem jurídica ou ordem de fato, uma vez que existe um grande debate quanto à interpretação do termo, que condiciona tanto a compreensão do teor dos próprios textos quanto suas possíveis formas de efetivação. Proponho analisar a expressão contida no art. 28 como ordem jurídica, entendendo-a não-só como reflexo de uma ordem de fato, que tem como característica ser desigual e injusta, mas em sua capacidade de se modificar e, assim, transformar a ordem de fato.

A pergunta que se coloca é: como implementar o Direito expresso no art. 28, que é o Direito a uma ordem internacional que garanta os Direitos Humanos? Uma visão moderna do Direito propõe que o consideremos não-só como instrumento de organização social, mas de mudança social. Nessa visão, desenvolvida por Bobbio, ${ }^{4}$ que revê a relação entre Direito e sociedade, entende-se a necessidade de

2. Norberto Bobbio, A Era dos Direitos, Rio de Janeiro, Campus, 1992, p. 28.

3. Ignacy Sachs, "O desenvolvimento enquanto apropriação dos direitos humanos", Revista de Estudos Avançados, v. 12, n. 33, 1998, pp. 149-156.

4. Celso Lafer, A Reconstrução dos Direito Humanos Um diálogo com o pensamento de Hannah Arendt, São Paulo, Companhia das Letras, 1988, p. 59. 

efetiva dos Direitos Humanos

encará-lo não apenas como determinação daquilo que é permitido ou proibido, mas, de um modo positivo, como capaz de redirecionar ou promover comportamentos. Assim, se a ordem de fato deve ser transformada, o que exigiria uma transformação na ordem jurídica em vigor, é ao próprio Direito que devemos recorrer para assegurar o direito a uma ordem, onde se veja garantida a apropriação efetiva dos Direitos Humanos.

Mas a ordem jurídica e o relacionamento interestatal, tal como se apresentam nos anos 90, não-só não vêm transformando a ordem de fato, como têm colocado obstáculos à implementação dos Direitos Humanos. Do ponto de vista do ordenamento jurídico internacional, o que proponho investigar é a questão da ordem econômica. A ordem internacional, entendida como a ordem que garante a segurança internacional, é obviamente fundamental. Nunca é demais repetir que sem paz não pode haver garantia dos Direitos Humanos e desenvolvimento. Mas cabe lembrar que os problemas relacionados a essas questões podem constituir graves ameaças à paz e à segurança internacional. Assim, pretendo tratar especificamente do aspecto econômico, e apontar para o fato de que a ordem jurídica econômica internacional vem colocando obstáculos à plena efetivação dos Direitos Humanos.

Como sabemos, uma ordem jurídica é composta por normas e instituições. Comecemos pelas primeiras. Quando se consideram as normas internacionais em vigor que têm incidência direta sobre a efetivação dos Direitos Humanos, percebe-se que elas, de fato, não vêm garantindo a ordem de que fala o art. 28 da Declaração Universal dos Direitos do Homem.

Nos anos 70, nutria-se a esperança de que haveria uma melhor distribuição da riqueza mundial, através das normas que compunham o chamado Direito Internacional do desenvolvimento. A elas caberia garantir aos países em desenvolvimento um tratamento preferencial, que traria como conseqüência direta a possibilidade de saírem da situação de "mau desenvolvimento" ${ }^{5} \mathrm{O}$ que se verifica hoje é um abandono dessas normas, suplantadas por outras que têm como fundamento a igualdade formal entre os diversos países e a defesa das virtudes da economia de mercado.

A idéia de um Direito Internacional Econômico como fator de controle e limitação do poder econômico absoluto dos atores em posição dominante, quer sejam Estados, quer empresas privadas, é substituída, na óptica globalizante, por um 
direito de promoção dos negócios, de garantia do livre mercado e de eliminação de barreiras à livre circulação de bens e capitais, perdendo, assim, qualquer controle sobre a hegemonia de determinados Estados ou de empresas multinacionais.

$E$ as instituições? No campo das organizações internacionais, o que se verifica é sua incapacidade de garantir uma ordem onde os Direitos Humanos possam ser efetivamente apropriados. Além de o Fundo Monetário Internacional (FMI) mostrar-se incapaz de controlar os acontecimentos recentes, observados no sistema financeiro e monetário internacional, também os ajustes estruturais propostos por esta instituição aos países necessitados de empréstimos prejudicam o gozo de direitos econômicos, sociais e culturais, como atestam veementemente os relatórios da Comissão de Direitos Humanos da ONU. ${ }^{6}$

A seu turno, a Organização Internacional do Comércio (OMC), que pode ser efetiva no sentido de promover o livre-comércio, deixa a desejar no que se refere à garantia dos Direitos Humanos. O tratamento preferencial aos países em desenvolvimento, que se estabeleceu tradicionalmente através do sistema geral de preferências (SGP) no âmbito do comércio internacional, tornou-se residual ou quase inexistente nesse novo sistema comercial. O tratamento das práticas comerciais desleais, o controle das atividades das empresas multinacionais, atividades que em muitas de suas facetas são obstáculos à efetivação dos direitos do homem, como também atestam os relatórios da $\mathrm{ONU}^{7}{ }^{7}$ praticamente desapareceram da agenda internacional.

Um exemplo gritante de como as regulamentações da OMC podem ser prejudiciais aos Direitos Humanos é o Acordo sobre Direitos de Propriedade Intelectual relacionados ao Comércio (TRIPs), que dá à organização poder de jurisdição internacional sobre a propriedade intelectual. O resultado da aplicação das normas ali contidas poderá restringir ainda mais a transferência de tecnologia, criar

6. ONU. Commission des Droits de L'Homme. Rapport du Groupe de Travail à composition non limitée sur les programmes d'ajustement structurel et les droits économiques, sociaux et culturels. E/CN.4/1997/20.

7. ONU. Commission on Human Rights. The Realization of Economic, Social and Cultural Rights. The Relationship between the enjoyment of human rights, in particular, international labour and trade union rights, and the working methods and activities of transnational corporations. E/CN.4/Sub.2/1995/1.

ONU. Commission on Human Rights. The Impact of the activities and working methods of transnational corporations on the full enjoyment of all human rights, in particular economic, social and cultural rights and the right to development, bearing in mind existing international guidelines, rules and standards relating to the subject-matter. E/CN.4/Sub.2/1996/12. 

efetiva dos Direitos Humanos

monopólios no que se refere ao conhecimento científico aplicado à produção e encarecer os produtos patenteados. Estão em causa o direito à saúde, o direito à alimentação e o direito à distribuição eqüitativa dos benefícios das descobertas da ciência e dos avanços da tecnologia. A questão das patentes, como se sabe, interessa especialmente ao Brasil, na medida em que a enorme riqueza da floresta amazônica em biodiversidade e a igualmente notável riqueza em formas tradicionais de manejo desses recursos tornam essa região talvez o principal palco de discussão.

Tendo em vista as considerações acima, a conclusão a que se chega é que as relações de poder no mundo estão refletidas nas estruturas jurídicas em que hoje se negociam e se codificam as questões da ordem econômica internacional contemporânea. Houve um deslocamento das negociações das questões econômicas, antes decididas essencialmente no foro das Nações Unidas, através de seu Conselho Econômico e Social, para instituições exclusivamente econômicas e comerciais. Tal fato deriva de um movimento maior, que vem ocorrendo paralelamente à chamada crise das Nações Unidas, no sentido de se esvaziarem as instituições voltadas para as questões sociais e de se fortalecerem, graças aos países desenvolvidos, as instituições de cunho puramente comercial ou econômico. Nessas instituições, os países desenvolvidos decidem as questões muitas vezes hegemonicamente, a exemplo do voto ponderado, como ocorre no FMI e no Banco Mundial.

Diante do exposto, percebemos que os caminhos para a busca de uma ordem internacional mais justa estão bloqueados nos foros em que se codificam as questões econômicas. Se a ordem, tal como se apresenta, principalmente a ordem jurídica internacional em vigor, é um obstáculo à implementação dos Direitos Humanos e se as instituições e regras não-garantem a apropriação efetiva desses direitos, resta propor o caminho inverso. Por que não aplicar diretamente o ordenamento jurídico dos Direitos Humanos às questões econômicas, em vez de esperar que as decisões econômicas cumpram o que determina o art. 28 da Declaração Universal? Insere-se nessa visão a proposta de Ignacy Sachs, ${ }^{8}$ que defende a formulação de políticas públicas de desenvolvimento centradas na promoção dos Direitos Humanos.

Desse modo, um dos caminhos possíveis para impedir o círculo vicioso que se estabelece entre o jogo de poder das nações e as instituições e normas internacionais seria aplicar os Direitos Humanos como instrumentos de mudança da

8. Ignacy Sachs, op. cit., p. 153. 
ordem. Uma proposta importante neste sentido é a da implementação de um direito ao desenvolvimento como parte integrante dos direitos fundamentais do homem. Por meio desse direito, declarado pela Assembléia Geral da ONU em 1986, reafirmado na ECO 92 e consagrado, definitivamente, na Conferência Mundial de Direitos Humanos de Viena, de 1993, todo ser humano e todos os povos têm o direito de participar e de contribuir para o desenvolvimento econômico, social, cultural e político, que permita a realização de todos os direitos do homem e de todas as liberdades fundamentais.

O direito ao desenvolvimento é um direito que, incorporando todos os Direitos Humanos reconhecidos, os afirma e os integra, para dar impulso efetivo à instituição de uma ordem econômica mais justa. O direito ao pleno desenvolvimento do indivíduo ao mesmo tempo condiciona e subentende o direito ao desenvolvimento dos povos e países, já que o desenvolvimento dos países pode servir à melhoria das circunstâncias econômicas, sociais e culturais de seus habitantes, desde que os benefícios decorrentes do desenvolvimento alcançado sejam eqüitativamente distribuídos.

Sendo assim, podemos entender que o direito ao desenvolvimento, na medida em que reflete a necessidade de integrar e coordenar o conjunto de direitos e deveres dos Estados e dos Direitos Humanos, tem como objetivo tornar possível a realização e implementação do art. 28 da Declaração Universal dos Direitos do Homem.

Para tornar mais concreta essa afirmação, lembraria que uma das tarefas do grupo de trabalho sobre direito ao desenvolvimento, que se reúne periodicamente no âmbito da Comissão de Direitos Humanos da ONU, é a identificação dos obstáculos à realização deste direito presentes na ordem internacional, tais como: a desigualdade de participação dos países em desenvolvimento na tomada de decisões econômicas nos foros internacionais, as atividades das empresas multinacionais, o peso das dívidas externas dos países em desenvolvimento, as medidas coercitivas econômicas unilaterais e a concentração do poder econômico, financeiro e tecnológico nas mãos de um número limitado de países.

Uma nova ordem jurídica, baseada no direito ao desenvolvimento, entendido como um sistema de integração de todos os direitos contidos na Declaração Universal, poderia alterar a ordem de fato. Pode-se argumentar que a idéia de um direito ao desenvolvimento é demasiadamente ambiciosa, mas cabe 
lembrar, como contra-argumento, a afirmação de Celso Furtado ${ }^{9}$ de que o desenvolvimento, mais que transformação, é invenção, e a análise de Celso Lafer ${ }^{10}$ que sublinha a relevância do poder da imaginação na produção dos argumentos para adensar juridicamente os Direitos Humanos, já que o reconhecimento de um valor é condição necessária mas não suficiente para sua realização histórica.

São Paulo, março de 1999.

9. Celso Furtado, Cultura e Desenvolvimento em época de crise, Rio de Janeiro, Paz e Terra, 1984, p. 105. Ignacy Sachs, "L'imagination et le savoir: le développement selon Celso Furtado". Cahiers du Brésil Contemporain, Paris, n. 33, 1998, pp. 179-183.

10. Celso Lafer, "Prefácio" a Direito ao Desenvolvimento e Investimentos Estrangeiros, de Cláudia Perrone-Moisés, São Paulo, Oliveira Mendes, 1998, p. XIII. 